Article

\title{
Setting up Energy Efficiency Management in Companies: Preliminary Lessons Learned from the Petroleum Industry
}

\author{
Bartlomiej Gawin 1 and Bartosz Marcinkowski * \\ Department of Business Informatics, Faculty of Management, University of Gdansk, Piaskowa 9, \\ 81-864 Sopot, Poland; bartlomiej.gawin@ug.edu.pl \\ * Correspondence: bartosz.marcinkowski@ug.edu.pl
}

Received: 19 September 2020; Accepted: 24 October 2020; Published: 27 October 2020

\begin{abstract}
In the era of expensive energy carriers and care for the climate, companies are keen to take action towards bolstering energy efficiency. Businesses often lack data on actual energy consumption to date, are rarely equipped with adequate analytical tools, and do not have the know-how regarding the transition itself. Developing energy efficiency management (EEM) for a given enterprise requires many steps, which ultimately unleash analytical potential and seamlessly integrate the EEM framework with the business model of a given company. This study scrutinizes and formalizes a reference process of pilot EEM implementation that involves external business partners in a multi-facility organization. The process is tailored to the specificity of the company's operations as well as its technical and management capabilities regarding energy efficiency. The proposed approach, phased in time and involving multiple stakeholders, should be especially useful for practitioners running EEM-related projects characterized by uncertain and changing requirements.
\end{abstract}

Keywords: energy use efficiency; energy efficiency management; design science research; pilot implementation

\section{Introduction}

Historically, economic growth proved to be linked to levels of energy consumption. Tugcu, Ozturk, and Aslan argued that this is the case for both renewable and non-renewable energy consumption [1]. At the same time, rising energy consumption results in excessive carbon dioxide $\left(\mathrm{CO}_{2}\right)$ emission as the most prevalent long-lasting greenhouse gas [2] and the most important greenhouse gas with regards to human activity. In effect, climate change may be positioned among crucial challenges of modern times. Energy efficiency (EE) is highlighted as the largest emissions growth restraint [3] and one of the widely acknowledged measures to meet the goal of keeping the increase in average global temperature well below $2{ }^{\circ} \mathrm{C}$ above pre-industrial levels according to the Paris Agreement [4]. Thus, societies put considerable hopes on it to mitigate the negative environmental impact and achieve sustainable economic development in the long run [5].

EE may be considered a distinctive feature of the products concerned [6], as well as a habitat preservation method that does not incur excessive costs, and at the same time, it provides companies with the opportunities for positive publicity [2]. The decision to take action to improve EE might be internal and resulting from purely economic reasons. That said, the pressure to shift towards more energy-efficient products, services, solutions, and behavioral patterns in terms of energy savings achieved is also likely to be enacted by governing bodies and institutions through energy efficiency policies (EEPs) [7]. Meeting the objectives of an EEP has a direct impact on the activity of companies operating within particular industries. All the actions taken by managers and employees of a given 
company to implement the rules and measures enforced by an EEP requires a properly developed business model [8]. On top of that, the results of these actions need to be monitored in order to verify whether the intended effects are achieved or not, and corrective actions are undertaken when necessary [9]. By tailoring business models, adapting business processes, rehauling, and deploying new IT solutions that support day-to-day EE-oriented management practices, the companies effectively establish energy efficiency management (EEM). The motivation behind this research was to extend the EE body of knowledge by understanding how consideration of EEPs and management practices necessary to implement them affects business models of real-world organizations.

Involving companies in EE programs is likely to exert influence on most components of their business models, regardless of the transformation strategies in place [10]. As implementing EEPs may come with substantial risks regarding the cash flow and bottom line of a company [11], such transition requires a good understanding of the constraints in place and demands on specific companies, as well as the core processes. Having a model of EEM tailored to the organization requires designing and implementing a process that features exploratory work and experiments. In our experience, all stages towards EEM - from the initial idea, through to evaluation, ensuring cost-effectiveness, actual financing, and implementation - should be considered. Therefore, the goal of this paper is to design and formalize the reference process of a pilot EEM implementation that involves external business partners in a multi-facility organization. The empirical study is fueled by three research questions:

RQ1: What key process steps and sources of information ought to be involved in the pilot implementation of EEM in a multi-facility organization?

RQ2: What level of telemetry and data processing systems involvement is expected to maintain EEM?

RQ3: How the structure of a contract between the organization that sets up EEM and an external EE solution provider should look like?

After the introduction, related research is discussed and the method is presented in Sections 2 and 3, respectively. Subsequently, the artifact as understood within the design science research is introduced, particularized, introduced to a real-life business organization, and validated. Section 5 discusses some best practices regarding post-pilot EE-focused activities between parties involved in setting up EEM based on the feedback collected during the study. Section 6 introduces the implications and limitations of the study, which are followed by conclusions.

\section{Research Background}

\subsection{EE and its Determinants}

Energy efficiency may be regarded as an integrative strategy for delaying climate change, taking care of energy security, and exerting a positive impact on economic development. EE implies using less energy to perform the same task; that is, eliminating energy waste [12]. In quantitative terms, EE constitutes a ratio between service outputs (result) and the energy input required to provide it [13]. Factors such as habits, attitude, awareness of EE measures, and perceptions of involved individuals have an impact on the EE [14]. On top of that, Chai and Baudelaire linked EE to organizational aspects and measurements [15]. Minimizing waste and reducing time or transport distances between succeeding production processes can improve EE, which is important from both environmental and business points of view since increased energy prices and costs related to emitting greenhouse gases affect the company's competitiveness [16].

Unfortunately, many organizations fail to take up the implementation of efficient EE measures due to financial determinants, insufficient information, and limited in-house skills [17]. That is why the concept of an energy efficiency gap, i.e., the discrepancy between actual and optimal energy use [18], has been introduced. This gap shows a paradox where the adoption of energy-efficient solutions is withheld despite anticipating a positive return on investment [19]. Fresner et al. argued that greater recognition of EE requires identification of what sort of direct and indirect benefits could be gained from adopting energy-efficient technologies [17]. 
Several factors contribute to the propagation of EE. Those include, but are not limited to:

- $\quad$ strictly market-related factors, such as awareness of actual energy costs, anticipating high market prices of energy in the future and subsequent attempts to constrain energy-related company costs, or availability of favorable loans for EE financing [20];

- advances within the organization and management, including the adoption of environmental management systems [21], benchmarking against competitors within a given industry, or enhancing supply chain management within a company [22];

- technological progress [23];

- environmental regulation at both national and regional levels [24], including increasing energy tariffs [25], drawing voluntary programs and agreements between industry and governing bodies that feature negotiated targets and timetables, as well as threatening to introduce future taxes/regulation [26].

The necessity to reduce costs were acknowledged as the main driver to EE, whereas corporate social responsibility, regulatory compliance, and available opportunities to implement EE, were found to have no significant effects on EE results [17]. These considerations were confirmed among others by Thollander et al., who noted that information-related determinants, such as the public sector being a role model, municipal membership in an EE program, or pressure from non-government organizations, had the least impact on the behavior of decision-makers [27].

\subsection{Energy Efficiency Policies}

EEPs might be regarded as abstract solutions to bolstering EE in a given legislative context. The development of an effective EEP is not a one-off activity. It is, in fact, a continuous, dynamic process that should establish conditions and rules for energy consumers and direct that change toward environmental and economic benefits. The policy-making cycle combines the design, implementation, and setting up of multiple criteria for evaluating policy instruments' impacts in a closed, repetitive loop. However, EEPs are not universal in nature or freely transferable between markets. To develop a policy tailored to the sector of the economy, one must understand the EE maturity level, and then develop a customized policy as well as to adapt it to the specifics of a business branch. Bukarica and Tomšić introduced the notion of the energy efficiency market as a concept for establishing EEPs; aside from appliance manufacturers, energy auditors, smart meter software designers, cogeneration developers, and their respective backgrounds, the market also covers sponsors, owners, authorities, and institutions that provide financing and assistance in the implementation of EE projects [6].

Many countries brought up initiatives targeted at promoting low-carbon development and improving EE in every sector of the economy that primarily features regulations and taxation [28]. On the other hand, Avgerinou, Bertoldi, and Castellazzi stress that the European Union and other major economies introduced policies and measures that are not punitive in nature [29]. Financial support policies constitute an important tool in that regard. In the Chinese market, two types of EE credits were implemented [30], enabling running EE projects with institutional support from financial institutions to counteract discontinuing investments due to the capital scarcity. As households and commercial building upgrades and retrofits are concerned, several programs may act as a benchmark for future ventures. From the USA market alone, the American Recovery and Reinvestment Act (ARRA) directed as much as $\$ 58$ billion towards EE; programs under ARRA targeted, inter alia, insulation of low-income homes as well lighting/appliance upgrades with more energy-efficient solutions [31].

Some instruments covered by policies are put in place in order to prompt interest in EE projects, while others aim to advance such projects from the early stages of development towards real-life implementation [6]. At the company level, EEPs must be integrated into organizational economic planning, technical and management conditions, and business development processes. A properly developed EEP ought to increase the maturity of management, the organizational structure of the company, as well as the competencies behind it; the joint effort of practitioners and researchers 
contributes to advancing the understanding of the relationship between improving EE in business organizations, the change processes responsible for that, and the drivers that affect these processes [19]. We argue that effective application of austerity policies proves to be a big challenge, however, their preparation, implementation, and continual improvement is even harder.

\subsection{Energy Efficiency Management}

Energy efficiency management applies to many business areas: data centers [29], manufacturing [17,19], wastewater treatment plants [32], industry [19,28], and facility management [33] to name just a few. EEM practices, tools, and models have been promoted as promising means of reducing energy consumption or improving energy efficiency [2]. Such practices can have a substantial impact on the profitability of not only energy-intensive companies but also those with low energy costs since the reduced energy expenditures directly lead to increased profits [16]. Research conducted by Backlund et al., highlighted that having both long-term energy strategies in place and employing committed energy managers with high skill sets proved to be important factors behind spurring EE in industrial companies [34]. While there is clearly a vast potential for improved efficiency in technology, Schulze et al. stressed that available sources addressing the implementation of various efficiency measures are highly biased towards this perspective and require further best-practices for achieving enhanced EE by introducing new routines and implementing customized processes within energy management [35].

Companies and individuals might not be aware of their actual energy-related expenses. Consequently, consumers and corporate decision-makers often do not possess sufficient information regarding the net benefits of investment in technologies that have higher EE levels [14] and credible information is crucial. Households that have information on their energy bill or energy consumption are not only more likely to invest in energy-efficient light sources and appliances, but there is also strong evidence that households who regularly perform low-cost energy conservation measures are also more likely to spend money to bolster EE [36]. Telemetry systems that have dedicated hardware components (i.e., sensors, meters) and IT solutions integrated with them are used to monitor and control energy consumption. Software components of such telemetry environments are often referred to as energy management systems. The data acquired may be then processed using business intelligence (BI) analytical systems, which enable seeking root causes of high electric power consumption as well as monitoring the effectiveness of activities in the area of EE.

In various organizations, EE projects ultimately aim to establish an EE management model that enables the reduction of both electric power consumption and $\mathrm{CO}_{2}$ emissions. Fernando and Hor analyzed a number of studies to come up with a list of activities that typically comprise the energy management process [2]:

- introducing review techniques that involve professionals who represent highly diversified business disciplines;

- $\quad$ scrutinizing historical data;

- performing energy audits;

- preparing feasibility analyses of energy improvement plans prepared by a business organization and possible implementation of those plans;

- conducting training in energy efficiency.

While both researchers and practitioners generally agree that business organizations may take advantage of multiple EE options, Fresner et al. point out that the more sophisticated of these options are often simply ignored [17]. Harris, Anderson, and Shafron showed that already in 2000, energy audits were likely to be among the first steps that any company might undertake when bolstering its EE, as the implementation rates of such audits were found to be high [37]. Although larger firms were overrepresented in their analysis, EE audits proved cost-effective and declared worthwhile by as many as $93 \%$ of the companies surveyed. Therefore, energy audits remain to be one of the leading instruments 
for introducing EEPs to overcome barriers to EE and to promote it. An energy audit may be considered a helpful tool for identifying opportunities and ascribing value to energy consumption to justify spending resources on EE projects [2]. Viable alternatives to energy audits feature a range of external energy services that cover contractual arrangements and funding mechanisms behind improving energy efficiency in a measurable way [27] and shifting towards a sustainable energy supply. Such services include energy performance contracting, third-party financing as well as contract energy management. A long-term EE strategy ought to be set up to take advantage of available options. According to Cai et al., an energy-saving and emission reduction (ESER) strategy promotes the sustainability of the manufacturing industry in green transition [28]. In order to address some ESER shortcomings (primarily the short completion timeframe required, lack of process standardization, and tariff-related issues), to improve the EE as well as to reduce waste emissions effectively, they introduce an enhanced concept based on lean principles, i.e., lean energy-saving and emission reduction.

\section{Methods}

To achieve the research goal, the design science research (DSR) method was used. DSR enabled evaluating artifacts from both a user-related and technical perspective [38]. Similarly to action research, the DSR addresses practical challenges while contributing to both practice and theory [39], thus gaining increasing recognition among information systems researchers in the process [40]. It was also successfully used to make designs that provide superior utility in the context of business process management [41]. As the current research delivered a formalization of a pilot EEM implementation process that involved external business partners in a multi-facility organization, the area of application of the method might be considered unconventional. It was, however, fully in line with the systematic literature review delivered by Offermann et al., who identified such artifact types as novel system designs, methods, languages/notations, algorithms, guidelines, requirements, patterns, or metrics [42].

Hevner et al. set forth seven guidelines that enhance the scientific rigor of the DSR approach [43]:

G1: an innovative, purposeful artifact ought to be created;

G2: the artifact must yield utility for a specified problem domain;

G3: the artifact is to be submitted for attentive evaluation;

G4: the artifact needs to address a heretofore unsolved challenge or feature a more effective solution to a well-known problem;

G5: the artifact itself must be strictly defined, internally consistent, and represented in a formal way;

G6: developing the artifact should involve a search process whereby a problem space is constructed, and a mechanism posed or enacted to find an effective solution;

G7: the outcomes of the DSR must be tellingly reported to practitioners responsible for putting them into practice, to the scientific community perfecting them, as well as to decision-makers, whose organizations shall take advantage of the artifact.

In order to (1) reliably assess the scope of data collected during the pilot EEM implementation process along with (2) determine the technological capability regarding automatic data collection; (3) narrow down the list of activities to those that show the greatest potential in terms of bolstering the $\mathrm{EE}$, and; (4) correctly plan its duration, a party with prior experience in offering EE services was required. Therefore, while developing the artifact, the researchers worked hand-in-hand with the staff of SDC Ltd., a specialized company running engineering activities and related technical consultancy with know-how on deploying telemetry in office buildings and retail facilities. Previous ventures that SDC had engaged in had differed greatly in scale and were not preceded by a standardized preparatory phase that enabled the assessment of the potential energy savings policies. Notwithstanding, their post-implementation reports, project schedules, and work order notes constituted primary data sources while developing the methodology.

The measurement solution used by the company is proprietary. A single control device was installed in the electrical switchboard of each customer's facilities. The device periodically transmitted 
a JSON frame with the electricity consumption snapshot, along with a list of additional parameters. The development of the artifact required testing the technological capabilities regarding tightening the interval of transmitting a set of data from the sensors experimentally, as well as analyzing the validity of taking additional parameters into account. It was concluded that the scalability of the analytics required admitting $\mathrm{CO}_{2}$ concentration, humidity, and internal temperature. Datasets were captured by an application implemented in the proven PHP/MySQL tandem. Some of its data processing functionalities were written in Scala. The application processed data and enabled the visualization of electricity consumption. It was possible to generate simple reports. More robust data analyses were performed by a BI solution based on the Qlik Sense engine. The solution took advantage of a data warehouse and enabled multi-dimensional data analyses by combining data from other sources. Those included but were not limited to, physical parameters of the facility, external weather data, and media-related invoices.

\section{Results}

\subsection{Conceptualization of the Artifact}

The artifact delivered by this study is shown at a high level of abstraction in Figure 1 . The abstract representation of the process was formalized using BPMN, as expected per the G5 guideline, and detailed in Table 1. The artifact introduced key steps, recommended sources of information regarding each facility, analytical determinants, EEM application areas that featured the most likely cost reduction opportunities as well as the projected timespan of the pilot EEM implementation. On top of that, the minimum number of facilities that ought to be equipped with telemetry was specified, and reference supporting IT solutions were singled out. Thus, the methodology directly addressed RQ1-2.

The pilot itself was designed for deployments in networked retail organizations. Under typical conditions, most dispersed facilities of such organizations do not have the means to diversify energy carriers and are strongly dependent on electricity prices. Regardless of the above, heating, ventilation, air conditioning, and refrigeration (HVACR) hardware had a significant share in their energy balance. Finally, energy consumption, at least partly, resulted from the necessity to operate some devices in a continuous mode (fuel pumps, air curtains). The pilot was generally expected to last 4 months since the telemetry had been deployed in all designated locations. The time required for installation and parametrization of measurement systems was dependent on the type of system used-in our case, the customer was provided with a complete solution to reduce the technological risk of the project. A reference value of two months was required to populate the telemetry database and to collect complementary EE-targeted data from the customer side. After these two months, austerity priorities were set and a test of the implementation of the measures resulting from these priorities was carried out. Further monitoring, adjustment, and a summary of pilot works were expected to last up to 2 months. 


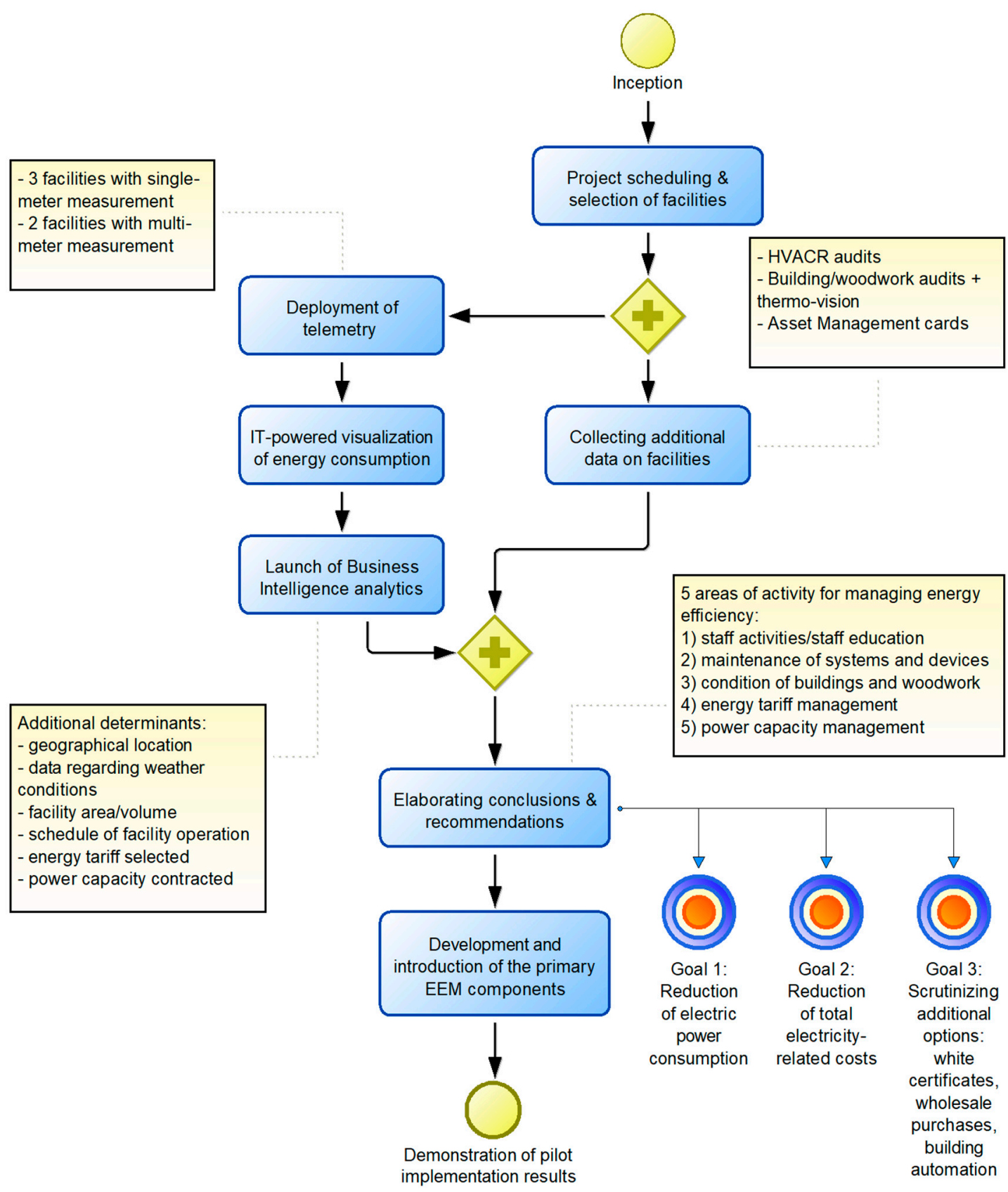

Figure 1. Reference process of a pilot energy efficiency management (EEM) implementation within a multi-facility organization.

Table 1. Description of pilot EEM implementation reference process steps.

\begin{tabular}{|c|c|}
\hline Step & Description \\
\hline Inception & $\begin{array}{l}\text { The prerequisites for the pilot works include the readiness of both the provider of a telemetry } \\
\text { system for measuring power consumption and the customer to jointly develop and test the } \\
\text { foundations of the EEM on a small pool of facilities. }\end{array}$ \\
\hline $\begin{array}{l}\text { Project scheduling \& } \\
\text { selection of facilities }\end{array}$ & $\begin{array}{l}\text { Five facilities shall be designated by the customer to create a pool of entities covered by pilot } \\
\text { works. Measurement of the power consumption exclusively on the main power input is assumed } \\
\text { regarding two facilities. Another two shall be provided with a multi-meter environment. Such an } \\
\text { approach enables performing test measurements for both configurations and identifying their } \\
\text { advantages and disadvantages. On top of selecting the facilities, a timetable and rules for } \\
\text { telemetry installations shall be worked out. }\end{array}$ \\
\hline \multicolumn{2}{|r|}{ Further steps to be carried out simultaneously } \\
\hline Step & Description \\
\hline
\end{tabular}


Table 1. Cont.

\begin{tabular}{|c|c|c|}
\hline Step & Description & \multirow{4}{*}{$\begin{array}{l}\text { In line with telemetry readings, } \\
\text { additional data on facilities shall } \\
\text { be collected and processed. } \\
\text { The sources of } \\
\text { knowledge include: } \\
\text { - } \quad \text { HVACR audits } \\
\text { - } \quad \text { building/woodwork audits } \\
\text { - } \quad \text { thermo-vision inspections } \\
\text { - } \quad \text { events generated as a part } \\
\text { of the facility } \\
\text { - } \quad \text { customer-side internal data } \\
\text { regarding } \\
\text { asset management }\end{array}$} \\
\hline Deployment of telemetry & $\begin{array}{l}\text { Putting the measurement } \\
\text { environment in place will not } \\
\text { require ceasing the operations of } \\
\text { any facility. Short breaks are } \\
\text { expected on some retail circuits } \\
\text { (HVACR, light sources). } \\
\text { The estimated duration of a } \\
\text { single installation varies from } 2 \\
\text { to } 6 \mathrm{~h} \text { per facility. }\end{array}$ & \\
\hline $\begin{array}{l}\text { IT-powered visualization of } \\
\text { energy consumption }\end{array}$ & $\begin{array}{l}\text { Consumption-related data are to } \\
\text { be visualized using a dedicated } \\
\text { IT solution. Access to reports } \\
\text { shall be provided via a web } \\
\text { browser. }\end{array}$ & \\
\hline $\begin{array}{l}\text { Launch of Business } \\
\text { Intelligence analytics }\end{array}$ & $\begin{array}{l}\text { Power consumption } \\
\text { measurements are to be } \\
\text { benchmarked against several } \\
\text { determinants: } \\
\text { - } \quad \text { the geographical location } \\
\text { of a given facility } \\
\text { - } \quad \text { weather conditions for this } \\
\text { - particular location } \\
\text { - } \quad \text { facility area or volume } \\
\text { - } \quad \text { facility operation } \\
\text { - } \quad \text { powergy tariff selected }\end{array}$ & \\
\hline \multicolumn{3}{|c|}{ Follow-through upon completing the aforementioned activities } \\
\hline Step & \multicolumn{2}{|l|}{ Description } \\
\hline $\begin{array}{l}\text { Elaborating conclusions } \mathcal{E} \\
\quad \text { recommendations }\end{array}$ & \multicolumn{2}{|c|}{$\begin{array}{l}\text { A document addressing cost reduction opportunities for the customer shall be delivered. } \\
\text { In particular, options to be explored in the following areas of EEM are to be unveiled: } \\
\text { - } \quad \text { staff activities/staff education } \\
\text { - } \quad \text { maintenance of systems and devices } \\
\text { - } \quad \text { condition of buildings and woodwork } \\
\text { - } \quad \text { energy tariff management } \\
\text { power capacity management }\end{array}$} \\
\hline $\begin{array}{l}\text { Development and } \\
\text { introduction of the primary } \\
\text { EEM components }\end{array}$ & \multicolumn{2}{|c|}{$\begin{array}{l}\text { Priority items that may be immediately streamlined in terms of EE are to be pointed out in this } \\
\text { phase. Such potential decisions include, but are not limited to, switching tariffs, rehauling or } \\
\text { fine-tuning devices, introducing simple automation of devices, forcing certain behaviors of the } \\
\text { staff, etc. }\end{array}$} \\
\hline $\begin{array}{l}\text { Demonstration of pilot } \\
\text { implementation results }\end{array}$ & \multicolumn{2}{|c|}{$\begin{array}{l}\text { A physical meeting of the interested parties that summarizes the works accomplished } \\
\text { throughout the implementation. }\end{array}$} \\
\hline
\end{tabular}

\subsection{Implementation and Validation of the Artifact}

DSR guidelines [43] directly stated that upon creation, the artifact needs to be evaluated (G3) and tellingly reported to interested parties (G7). In our case, both of those scientific rigor-oriented steps were effectuated jointly by the research teams and business partners as a part of the project aimed at enhancing EE within the network of facilities owned/franchised by the Polish subsidiary of a global player representing the petroleum industry. Royal Dutch Shell PLC, headquartered in the Netherlands, is included on a Global 2000 List of the World's Largest Public Companies, with \$394 billion total assets and over $\$ 311$ billion of revenue [44]. Its retail arm by the end of 2019 covered approx. 45 thousand facilities that operated based on different business models in close to 80 countries and handled over 30 million customer visits on a daily basis [45].

The pilot works implementation process unveiled two deviations from the original design of the artifact, i.e., the number of areas for EEM covered by pilot works and the length of the pilot itself. While the latter might be classified as minor, the former deserved special consideration. Pilot works 
were launched by selecting a pool of facilities (in this case: petrol stations) from among a total of over 400 facilities located in Poland. The methodology provided for designating two groups of facilities - with the first group being measured only at the main power input, and the second configured with multiple meters. Electrical circuits measured by the more sophisticated configuration included interior lighting sources of the station, air conditioning, and exterior lighting sources of a station (roofing, driveways, illuminated advertising, etc.). All the determinants necessary to initiate analytics (locations, weather conditions, volumes, schedules of operation, relevant contractual details between the customer and all energy suppliers involved) were provided, integrated, and double-checked.

Installing respective meters paved the way for collecting data on electric power consumption. Upon considering both the needs of the participating organization and the technical constraints, it was decided to send aggregated data packages from individual facilities every $15 \mathrm{~min}$. Electric power consumption was plotted as hourly bars and supported by the BI system in place. It related power consumption to the aforementioned determinants. Simultaneously, the collection of additional data to support these activities was launched. In line with the construction of the artifact, energy audits were conducted as a part of pilot works, and technical inspections of electrical devices, thermo-vision, and building/woodwork audits constituted the primary sources of additional data. Values and informational content, upon being subjected to analysis, influenced the EEM of each petrol station involved.

Of the five areas of activity for EEM that the initial concept envisaged, specific actions to be completed were listed within areas 1, 4, and 5 (see Figure 1). Areas 2 and 3 were excluded from the pilot works. Activities in the areas undertaken for implementation were carried out until the end of the pilot's timeframe. The work was concluded with several recommendations, including guidelines for staff behavior at stations, benchmarking the existing electric power tariffs against optimal ones, selection of new tariffs for each facility, and proposing reductions in contracted power levels. It was empirically confirmed that the actions within these three areas resulted in a net reduction in power costs at the designated petrol stations without compromising business continuity.

Ultimately, the pilot EEM implementation lasted from 1 January 2019 to the end of May. Project inception required 2 weeks and involved preparing measurement equipment, assembling installation teams, training on safety at work at petrol stations as well as scheduling telemetry installation. The actual deployment of telemetry in all five facilities totaled one month. Beginning in mid-February, every telemetry system started generating measurement data and forwarding it to the data processing IT solutions. While measurements were kept live until the end of the pilot works, at the end of February, early feedback and recommendations were determined. Between the beginning of March and the end of May, recommendations were introduced in all facilities, and the results were observed. Upon the pilot project completion, concluding workshops were held.

As energy services tend to be settled under performance-based contracts [27], the pilot served as a data source for elaborating pessimistic, realistic, and optimistic scenarios for increasing EE during the course of the actual contract. The pilot showed a statistically significant potential to reduce the nominal energy consumption. The specificity of petrol stations' operations (24/7 mode, excluding the short period where the customer-side systems settle daily transactions) contributed to power consumption not being reduced by late evenings and during night times. On the contrary, consumption is statistically lowest during (late) mornings and mid-day. This is when few light sources are used, and the Central European climate implies less intensive use of heating systems. Regardless of the above, the selection of energy tariffs, which were rational when signing contracts with energy suppliers, became less favorable over time. Tariff systems tended to become increasingly complicated, and the unbundled energy distribution market in Poland makes identifying optimal solutions on one's own, time-consuming. In this case, having an up-to-date tariff database that is for the needs of the entire customer portfolio significantly facilitates optimization processes. Whereas tariffs individually tailored to the profile of each facility where possible, show that time periods in which energy prices are higher than the base 
tariff (see Figure 2, the median case with a linear tariff), are more than compensated for over the rest of the day.

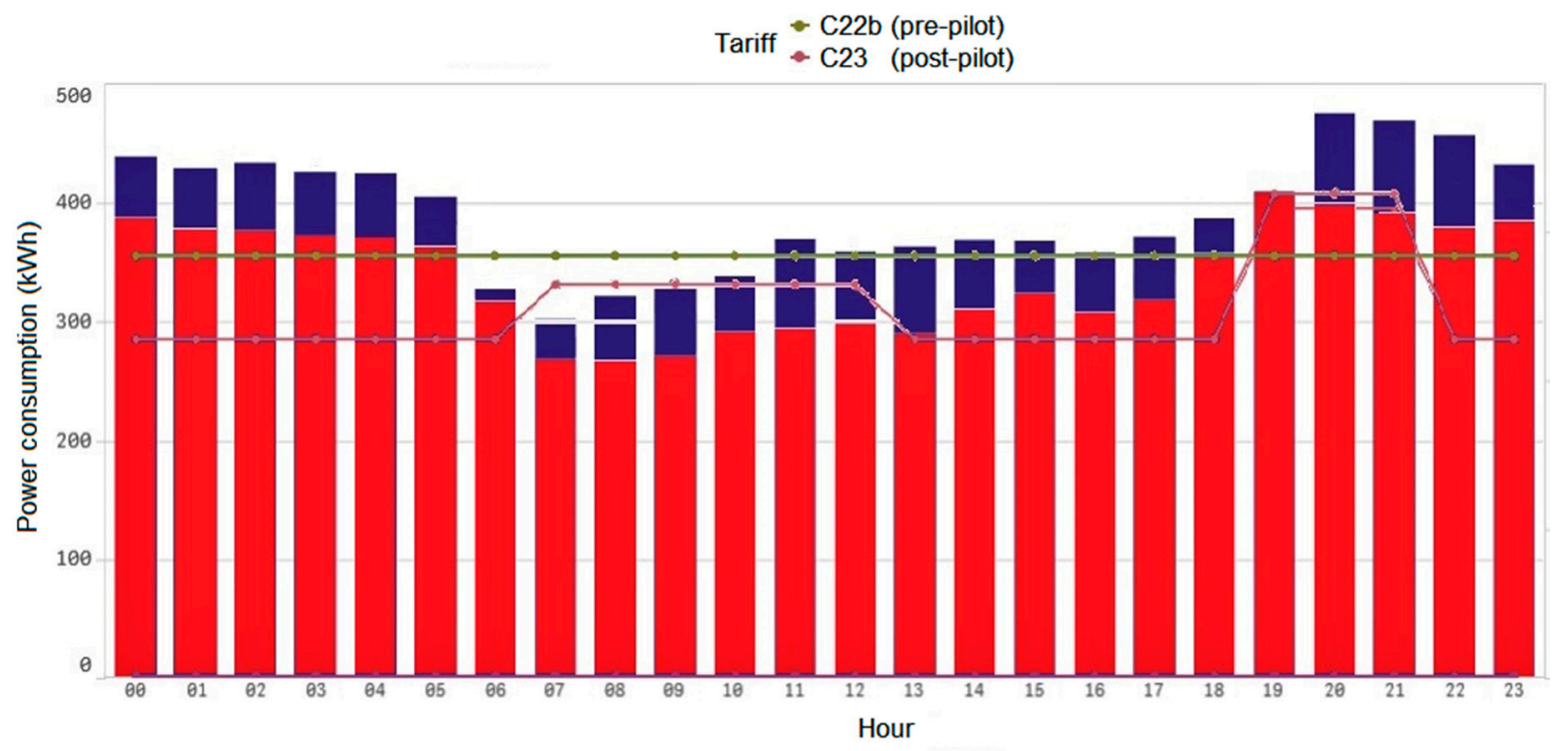

Figure 2. Differences in energy consumption and tariff adjustment.

Given the time necessary for reflection, the participating organization committed to up-scale their EE-oriented efforts to the entire network of Polish facilities by signing a 3-year contract at the end of June 2019. The pilot's pessimistic scenario for increasing EE was adopted as the benchmark for the contract. In its first year, which also covered the 5-month-long telemetry installation phase, the provider of the energy services took upon oneself achieving cumulative savings of $2.25 \%$ on one-third of the base amount. Throughout the second year of the contract, a significantly higher level of EE improvement was set: no less than $10 \%$ on two-thirds of the base amount. Such a scale of commitment was in line with the long-term estimates formulated in the post-pilot reports and the adjustments for unsupported areas of activity (see Table 2). The calculation took into account both the saturation of the telemetry system with data and the development and implementation of specific policies, as well as getting to know the facilities, personnel, and internal processes of the petrol company. Pilot-based projection indicated the need for a conservative approach in the final year (cumulative savings of $14 \%$ of the total base amount) due to reaching expected limits regarding opportunities for reducing electricity consumption without affecting the continuity of business.

Table 2. Post-pilot estimates regarding the scale of savings in the long run.

\begin{tabular}{ccc}
\hline Area of Activity & $\begin{array}{c}\text { Estimated Reduction in Power } \\
\text { Consumption } \\
\text { [\% of Current kWh] }\end{array}$ & $\begin{array}{c}\text { Estimated Cost Reduction } \\
\text { [\% of Pre-Implementation } \\
\text { Invoice Amounts] }\end{array}$ \\
\hline $\begin{array}{c}\text { Staff activities/staff education } \\
\text { Maintenance of systems and } \\
\text { devices }\end{array}$ & $7 \%$ & $7 \%$ \\
Condition of buildings and & $(7 \%)$ & $(7 \%)$ \\
woodwork & $(5 \%)$ & $(6 \%)$ \\
Energy tariff management & $\mathrm{n} / \mathrm{a}$ & $8 \%$ \\
Power capacity management & $\mathrm{n} / \mathrm{a}$ & $3 \%$ \\
\hline Total & & $18 \%(31 \%)$ \\
\hline
\end{tabular}




\section{Discussion}

The study demonstrated that EEM is, on one hand, a long-term process that requires continuous monitoring and improvement as well as adapting to constant changes both in the business environment and within the organization. While the necessity to take advantage of enhanced procedures and adapt business processes were explored before [35], lessons learned from this study are somewhat polemic with previous conclusions that companies are generally uninterested in ventures lasting beyond 3 years [17]. The recommended best practice in this respect is to stage the target contract so that periodical milestones/review points and success fees were considered (Table 3 ). In this very case, the progress is being monitored at weekly and monthly intervals. On top of that, once a year an official presentation of the savings recorded and details of the methods to achieve them is given to a wider audience of customer-side professionals, as indicated in the contract.

On the other hand, such a contract proves parameterizable to a large extent. The study showed that EEM implementation features selecting a set of options that do not exhaust all the possibilities but are favorable in a given horizon and budget/investment capabilities. In this case, three EE-improvement areas (human behavior, tariffs, capacity management) indeed required an investment in a telemetry system as well as developing and implementing an EEP. However, compared to the other preselected areas, it involved no additional costs related to upgrading/replacing electrical systems or conducting a general overhaul of a facility or its components (such as woodwork). Such fundamental ventures depend on the firmness of financial commitment from the investor and the lack thereof put the capability of meeting the conditions for success fee at risk. Hence, the recommended best practice in this regard is to scale down the list of potential EE improvement areas within the first $30 \%$ of the contract.

First-year performance indicators exceeded both the contract reference values and the average savings of approx. $5.0 \%$ reported by Fresner et al. based on the analysis of 280 EE-targeted projects across seven different countries [17]. It should be pointed out that the adoption of the pilot's pessimistic scenario did not increase the accuracy of forecasting the actual performance of the contract, which might be assumed based on the study by Fowlie et al. [46]. Similarly, actual energy savings in Zivin and Novan's analysis were off by $21 \%$ [47]. Nevertheless, the energy service implemented following the application of the methodology was beyond the scope of the energy audits covered by those analyses. Moreover, small/medium-sized enterprises have a natural tendency to avoid the more intrusive measures that a corporate body can easily afford, and whether the COVID-19 pandemic has had a noticeable impact on the results remains to be seen. Adopting realistic scenarios as benchmarks for similar contracts in our opinion requires pinpointing methods for calculating savings generated, which will take into account factors such as volatility of electric power prices, weather anomalies (atypically warm winters or hot summers), as well as fluctuations in equipment lists of relevant petrol stations. The latter involves, in particular, extra electrical hardware such as HVACR devices or (super) chargers for electric cars.

There is a need to highlight the strong feedback of the practitioners that the success of the project and assuring the efficacy of developed measures requires the involvement of employees from various levels, as well as adapting some business processes. This is in line with Johansson and Thollander's contribution, who listed top-management support as a leading success factor regarding EEM practices [16]. 
Table 3. Key activities within the EEM framework.

\begin{tabular}{|c|c|c|}
\hline Year & Phase of Contract & Description \\
\hline \multirow{3}{*}{1} & $\begin{array}{l}\text { The inception of the EE } \\
\text { improvement contract }\end{array}$ & $\begin{array}{l}\text { Based on the feedback of the pilot project implementation, } \\
\text { the contract between the interested parties shall be drafted } \\
\text { and then carried into effect. The contract itself aims to } \\
\text { reduce the electric power consumption/costs owing through } \\
\text { the design, implementation and continuously enhanced } \\
\text { EEM measures on the customer side. } \\
\text { Accomplishing the following tasks: }\end{array}$ \\
\hline & $\begin{array}{c}\text { Introduction of the EEM } \\
\text { measures }\end{array}$ & $\begin{array}{l}\text { installation of the dedicated telemetry system in all } \\
\text { facilities covered by the contract (refining the list of } \\
\text { facilities and deployment timetable is required; } \\
\text { measurement environments in individual facilities } \\
\text { shall be integrated with relevant service provider's IT } \\
\text { solutions at this stage) } \\
\text { taking advantage of EE improvement opportunities } \\
\text { within telemetry-ready facilities } \\
\text { identifying further options and areas for scaling up the } \\
\text { austerity policy }\end{array}$ \\
\hline & $\begin{array}{l}\text { Progress towards the goal } \\
\text { (1st-year milestone) }\end{array}$ & $\begin{array}{l}\text { Summarizing the first year of the contract. Verifying the } \\
\text { achievement of the adopted partial goals and indicators. } \\
\text { Laying down detailed goals and indicators for the following } \\
\text { year. }\end{array}$ \\
\hline \multirow[t]{2}{*}{2} & $\begin{array}{c}\text { Refinement and monitoring of the } \\
\text { EEM measures }\end{array}$ & 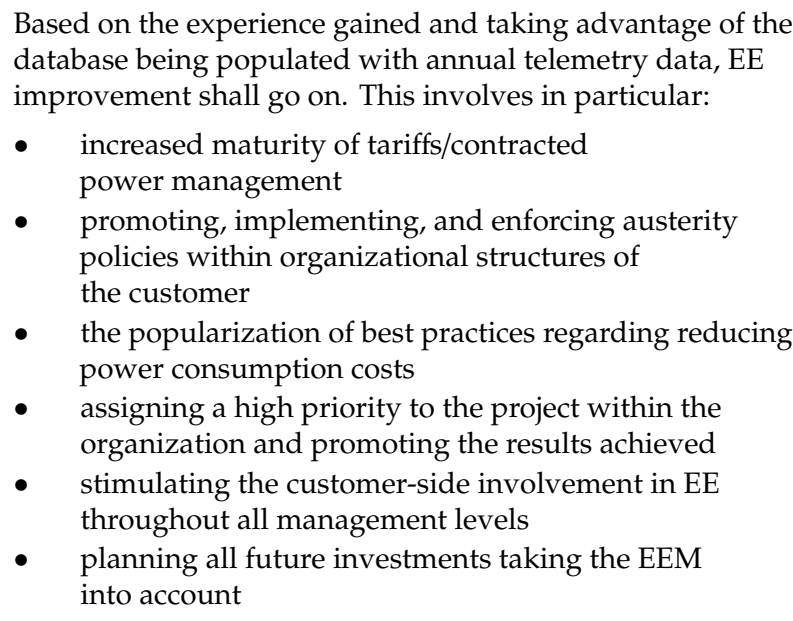 \\
\hline & $\begin{array}{l}\text { Progress towards the goal } \\
\text { (2nd-year milestone) }\end{array}$ & $\begin{array}{l}\text { Summarizing the second year of the contract. Verifying the } \\
\text { achievement of the adopted partial goals and indicators. } \\
\text { Laying down detailed goals and indicators for the final year. }\end{array}$ \\
\hline 3 & $\begin{array}{c}\text { Development and diffusion of the } \\
\text { EEM measures }\end{array}$ & $\begin{array}{l}\text { Cleaning the project backlog of implementation-related } \\
\text { activities, continuous improvement, and verifying the } \\
\text { efficacy of measures in place. Adjusting all internal business } \\
\text { processes on the customer side in line with the EE } \\
\text { improvement best practices and available toolset. } \\
\text { Summarizing the third year of the contract. Verifying the } \\
\text { achievement of the adopted partial goals and indicators. } \\
\text { Laying down detailed goals and indicators for the } \\
\text { foreseeable future. }\end{array}$ \\
\hline $\mathrm{N} / \mathrm{A}$ & $\begin{array}{c}\text { Continuous use and development } \\
\text { of EEM }\end{array}$ & $\begin{array}{l}\text { Further workflows related to developing techniques, tools, } \\
\text { and best practices in EEM. Maintaining results achieved } \\
\text { to date. }\end{array}$ \\
\hline
\end{tabular}




\section{Implications and Limitations}

\subsection{Implications for Theory and Practice}

The current study's results suggest several implications for both researchers and practitioners in the field of energy efficiency management. First of all, EE-enhancement ventures can all too often be brought down to a direct transposition of success stories advertised across other industries by the boards of implementing companies or capitalizing on to-date experiences of operational departments of energy service providers in the shortest timeframe possible. As multinational companies stretch their dispersed networks of facilities across locations with diametrically different local media tariffs, weather conditions, construction-related laws and practices, facility work schedules, or even cultural habits, such approach often fails to deliver $[17,47]$. The current study's findings strongly imply that a multiple-stakeholder perspective must be employed while implementing EEM. Various stakeholders' needs, expectations, and constraints must be carefully estimated, managed, and reconciled. Managing such a diverse set of considerations requires time, which illustrates the second major implication stemming from our study: time-related complexity. In this respect, our findings suggest that in order to manage EEM-related endeavors effectively, an approach phased in time ought to be adopted. Such an approach should allow practitioners to reasonably estimate and mitigate risks associated with the full-scope EEM implementation projects and make an informed decision about the project launching. Empirical data obtained thanks to the implementation of the artifact can also be a valuable argument while obtaining external financing, as both escalating the telemetry onto the entire facility network and overhauling individual facilities go in line with discernible investments. The phased approach to managing IT adoption projects is especially advised in changeable economic settings that result in a volatile nature of project requirements [48].

We extended the list of activities that usually cover the energy management process [2] by pinpointing the areas within which actions should be taken to manage energy efficiency. While fully acknowledging prior conclusions that energy audits allow us to determine what affects electricity losses [17], we demonstrated that pilot actions enable establishing why these losses occur-which in turn paves the way for a long-term organizational EE strategy. The framework proposed and discussed in the study may be applied in organizations of similar characteristics to those researched in the current paper. In particular, adopting an implementation approach phased in time and the use of suggested IT solutions such as sensors, data gathering, and analytical tools should help managers to better capture and manage multi-faceted considerations experienced by EEM projects. As a result, a fuller insight into the energy-related considerations might impact strategic decisions such as those related to a company's business model or business process reengineering.

\subsection{Limitations and Potential Future Research Directions}

The primary limitations of the current study are associated with the research setting, which features business units (petrol stations) of a global company operating on the Polish petroleum market. First of all, although facilities of this type might appear similar to other businesses-such as retail or grocery stores-when energy-related considerations are taken into account, it should be born in mind that a petrol station has its intricacies which might impact the generalization of findings to other industries. Secondly, the country of investigation within the current study, Poland, is an example of a transition economy and, as compared to the most industrialized economies, reveals a number of specific considerations such as the lack of a strategic ICT role, insufficient customer orientation, and the critical role of people-related issues [49]. Therefore, the generalization of the current study's results to other economic settings should be done with caution.

It would appear that a cross-industry and cross-country investigation into EEM is an important direction of future research. A promising focus for potential studies is mapping energy consumption carriers per industry and per specific field that are either rigid or susceptible to intensive optimization without entertaining risk factors. Researchers and practitioners alike are also interested in how 
extensively the increased EE of retail facilities translates into the total carbon footprint of the products or services provided.

\section{Conclusions}

Within the current study, the DSR's artifact-being a formalized version of a reference EEM implementation process for multi-facility companies-was conceptualized, implemented, evaluated, and escalated from pilot works towards a country-wide project. The target EE improvement contract were spread over 400 petrol stations. Our research explored key process steps, sources of information (RQ1), reference telemetry, and data processing solutions (RQ2) as well as guidelines for framing EE improvement contracts between implementing organizations and contractors (RQ3). The study enabled us to identify areas for improving EE. It was confirmed that the involvement of customer-side staff in the implementation, verification, and continuous improvement of EEM measures was crucial. Close cooperation between the petroleum company that hosted the pilot works and the supplier of telemetric and analytical tools that fully committed itself to support EE improvement activities also contributed to the success of the project.

Nowadays, an effective EEM without mature IT is virtually impossible. A multitude of complex tariffs used by multiple power suppliers, analytical challenges, patterns, and projections that quickly lose relevance, as well as the relative diversity of implementation environments, all highlights the value of IT for EEM. Detailed knowledge regarding the volume of electric power consumption and its distribution over time ought to be adequately captured, up-to-date, and easy to access. Such serviceable knowledge enables matching appropriate energy tariffs perfectly and ordering power volumes that are technically and economically justified. Capable tools combined with know-how and efficiency of operations lead to achieving significant savings.

Author Contributions: Conceptualization, B.G.; methodology, B.M.; validation, B.G.; formal analysis, B.M. and B.G.; investigation, B.M.; writing-original draft preparation, B.M.; writing-review and editing, B.G.; visualization, B.M.; supervision, B.M.; project administration, B.G.; funding acquisition, B.G. All authors have read and agreed to the published version of the manuscript.

Funding: This study was funded by the National Centre for Research and Development (PL)—competition for micro, small and medium enterprises that have received the Seal of Excellence in SME Instrument competitions, phase II (Horizon 2020). Grant number POIR.01.01.01-00-0003/19. The co-author of the article, B.G., is the author of the application, which obtained funding for research and development works.

Acknowledgments: We would hereby like to thank Piotr Soja for his constructive criticism regarding the initial version of the manuscript.

Conflicts of Interest: The authors declare no conflict of interest. The funders had no role in the design of the study; in the collection, analyses, or interpretation of data; in the writing of the manuscript, or in the decision to publish the results.

\section{References}

1. Tugcu, C.T.; Ozturk, I.; Aslan, A. Renewable and non-renewable energy consumption and economic growth relationship revisited: Evidence from G7 countries. Energy Econ. 2012, 34, 1942-1950. [CrossRef]

2. Fernando, Y.; Hor, W.L. Impacts of energy management practices on energy efficiency and carbon emissions reduction: A survey of malaysian manufacturing firms. Resour. Conserv. Recycl. 2017, 126, 62-73. [CrossRef]

3. International Energy Agency. Global Energy \& $\mathrm{CO}_{2}$ Status Report. 2019. Available online: https: //iea.org/reports/global-energy-co2-status-report-2019 (accessed on 12 October 2020).

4. United Nations. Report of the Conference of the Parties on its Twenty-First Session. Addendum Part Two: Action Taken by the Conference of the Parties at its Twenty-First Session. Available online: https: //unfccc.int/resource/docs/2015/cop21/eng/10a01.pdf (accessed on 12 October 2020).

5. Saboori, B.; Sulaiman, J.; Mohd, S. Economic growth and $\mathrm{CO}_{2}$ emissions in malaysia: A cointegration analysis of the environmental kuznets curve. Energy Policy 2012, 51, 184-191. [CrossRef]

6. Bukarica, V.; Tomšić, Ž. Energy efficiency policy evaluation by moving from techno-economic towards whole society perspective on energy efficiency market. Renew. Sustain. Energy Rev. 2017, 70, 968-975. [CrossRef] 
7. Cooremans, C.; Schönenberger, A. Energy management: A key driver of energy-efficiency investment? J. Clean. Prod. 2019, 230, 264-275. [CrossRef]

8. May, G.; Kiritsis, D. Business model for energy efficiency in manufacturing. Procedia Cirp. 2017, 61, 410-415. [CrossRef]

9. Marcinkowski, B.; Gawin, B. Data-driven business model development-Insights from the facility management industry. J. Facil. Manag. 2020, earlycite. [CrossRef]

10. Gauthier, C.; Gilomen, B. Business models for sustainability: Energy efficiency in urban districts. Organ. Environ. 2016, 29, 124-144. [CrossRef]

11. Hilorme, T.; Zamazii, O.; Judina, O.; Korolenko, R.; Melnikova, Y. Formation of risk mitigating strategies for the implementation of projects of energy saving technologies. Acad. Strateg. Manag. J. 2019, 18, 1-6.

12. Environmental and Energy Study Institute. Energy Efficiency. Available online: https://www.eesi.org/topics/ energy-efficiency/description (accessed on 7 March 2020).

13. Pérez-Lombard, L.; Ortiz, J.; Velázquez, D. Revisiting energy efficiency fundamentals. Energy Effic. 2013, 6, 239-254. [CrossRef]

14. Bhardwaj, K.; Gupta, E. Analyzing the "energy-efficiency gap". Indian Growth Dev. Rev. 2017, 10, 66-88. [CrossRef]

15. Chai, K.-H.; Baudelaire, C. Understanding the energy efficiency gap in Singapore: A motivation, opportunity, and ability perspective. J. Clean. Prod. 2015, 100, 224-234. [CrossRef]

16. Johansson, M.T.; Thollander, P. A review of barriers to and driving forces for improved energy efficiency in swedish industry-Recommendations for successful in-house energy management. Renew. Sustain. Energy Rev. 2018, 82, 618-628. [CrossRef]

17. Fresner, J.; Morea, F.; Krenn, C.; Uson, J.A.; Tomasi, F. Energy efficiency in small and medium enterprises: Lessons learned from 280 energy audits across Europe. J. Clean. Prod. 2017, 142, 1650-1660. [CrossRef]

18. Jaffe, A.B.; Stavins, R.N. The energy-efficiency gap. What does it mean? Energy Policy 1994, 22, 804-810. [CrossRef]

19. Solnørdal, M.T.; Foss, L. Closing the energy efficiency gap-A systematic review of empirical articles on drivers to energy efficiency in manufacturing firms. Energies 2018, 11, 518. [CrossRef]

20. Hasan, A.S.M.; Rokonuzzaman, M.; Tuhin, R.A.; Salimullah, S.M.; Ullah, M.; Sakib, T.H.; Thollander, P. Drivers and barriers to industrial energy efficiency in textile industries of Bangladesh. Energies 2019, 12, 1775. [CrossRef]

21. Zobel, T.; Malmgren, C. Evaluating the management system approach for industrial energy efficiency improvements. Energies 2016, 9, 774. [CrossRef]

22. Marchi, B.; Zanoni, S. Supply chain management for improved energy efficiency: Review and opportunities. Energies 2017, 10, 1618. [CrossRef]

23. Wang, C.N.; Ho, H.X.T.; Hsueh, M.H. An integrated approach for estimating the energy efficiency of seventeen countries. Energies 2017, 10, 1597. [CrossRef]

24. Lin, J.; Xu, C. The impact of environmental regulation on total factor energy efficiency: A cross-region analysis in China. Energies 2017, 10, 1578. [CrossRef]

25. Cagno, E.; Trianni, A.; Spallina, G.; Marchesani, F. Drivers for energy efficiency and their effect on barriers: Empirical Evidence from Italian manufacturing enterprises. Energy Effic. 2016, 10, 855-869. [CrossRef]

26. Worrell, E.; Bernstein, L.; Roy, J.; Price, L.; Harnisch, J. Industrial energy efficiency and climate change mitigation. Energy Effic. 2009, 2, 109. [CrossRef]

27. Thollander, P.; Backlund, S.; Trianni, A.; Cagno, E. Beyond barriers-A case study on driving forces for improved energy efficiency in the foundry industries in Finland, France, Germany, Italy, Poland, Spain, and Sweden. Appl. Energy 2013, 111, 636-643. [CrossRef]

28. Cai, W.; Lai, K.-H.; Liu, C.; Wei, F.; Ma, M.; Jia, S.; Jiang, Z.; Lv, L. Promoting sustainability of manufacturing industry through the lean energy-saving and emission-reduction strategy. Sci. Total Environ. 2019, 665, $23-32$. [CrossRef]

29. Avgerinou, M.; Bertoldi, P.; Castellazzi, L. Trends in data centre energy consumption under the european code of conduct for data centre energy efficiency. Energies 2017, 10, 1470. [CrossRef]

30. Yuan, X.; Ma, R.; Zuo, J.; Mu, R. Towards a sustainable society: The status and future of energy performance contracting in China. J. Clean. Prod. 2016, 112, 1608-1618. [CrossRef] 
31. Tang, T.; Hill, H. Implementation and impacts of intergovernmental grant programs on energy efficiency in the USA. Curr. Sustain. Renew. Energy Rep. 2018, 5, 59-66. [CrossRef]

32. Guerrini, A.; Romano, G.; Indipendenza, A. Energy efficiency drivers in wastewater treatment plants: A double bootstrap DEA analysis. Sustainability 2017, 9, 1126. [CrossRef]

33. Gawin, B.; Marcinkowski, B. Business intelligence in facility management: Determinants and benchmarking scenarios for improving energy efficiency. Inf. Syst. Manag. 2017, 34, 347-358. [CrossRef]

34. Backlund, S.; Thollander, P.; Palm, J.; Ottosson, M. Extending the energy efficiency gap. Energy Policy 2012, 51, 392-396. [CrossRef]

35. Schulze, M.; Nehler, H.; Ottosson, M.; Thollander, P. Energy management in industry-A systematic review of previous findings and an integrative conceptual framework. J. Clean. Prod. 2016, 112, 3692-3708. [CrossRef]

36. Ameli, N.; Brandt, N. Determinants of households' investment in energy efficiency and renewables: Evidence from the OECD survey on household environmental behaviour and attitudes. Environ. Res. Lett. 2015, 10, 044015. [CrossRef]

37. Harris, J.; Anderson, J.; Shafron, W. Investment in energy efficiency: A survey of Australian firms. Energy Policy 2000, 28, 867-876. [CrossRef]

38. Riehle, D.M.; Fleischer, S.; Becker, J. A web-based information system to evaluate different versions of IT artefacts in online experiments. AIS Trans. Enterp. Syst. 2019, 4, 10. [CrossRef]

39. Stal, J.; Paliwoda-Pekosz, G. Fostering development of soft skills in ICT curricula: A case of a transition economy. Inf. Technol. Dev. 2019, 25, 250-274. [CrossRef]

40. March, S.T.; Storey, V.C. Design science in the information systems discipline: An introduction to the special issue on design science research. Mis. Q. 2008, 32, 725-730. [CrossRef]

41. Mendling, J. From scientific process management to process science: Towards an empirical research agenda for business process management. In Proceedings of the 8th ZEUS Workshop, Vienna, Austria, 27-28 January 2016; pp. 1-4.

42. Offermann, P.; Blom, S.; Schönherr, M.; Bub, U. Artifact types in information systems design science-A literature review. Lect. Notes Comput. Sci. 2010, 6105, 77-92. [CrossRef]

43. Hevner, A.R.; March, S.T.; Park, J.; Ram, S. Design science in information systems research. Mis. Q. 2004, 28, 75-105. [CrossRef]

44. Murphy, A.; Tucker, H.; Coyne, M.; Touryalai, H. GLOBAL 2000. The World's Largest Public Companies; Forbes: Jersey City, NJ, USA, 2020.

45. Coulter, L.M. Energy for a better future. Annual Report and Accounts for the Year Ended December 31, 2019; Royal Dutch Shell PLC: Hague, The Netherlands, 2020.

46. Fowlie, M.; Greenstone, M.; Wolfram, C. Do energy efficiency investments deliver? Evidence from the weatherization assistance program. Q. J. Econ. 2018, 133, 1597-1644. [CrossRef]

47. Zivin, J.G.; Novan, K. Upgrading efficiency and behavior: Electricity savings from residential weatherization programs. Energy J. 2016, 37, 1-24. [CrossRef]

48. Themistocleous, M.; Soja, P.; Cunha, P.R. The same, but different: Enterprise systems adoption lifecycles in transition economies. Inf. Syst. Manag. 2011, 28, 223-239. [CrossRef]

49. Soja, P.; Cunha, P.R. ICT in transition economies: Narrowing the research gap to developed countries. Inf. Technol. Dev. 2015, 21, 323-329. [CrossRef]

Publisher's Note: MDPI stays neutral with regard to jurisdictional claims in published maps and institutional affiliations.

(C) 2020 by the authors. Licensee MDPI, Basel, Switzerland. This article is an open access article distributed under the terms and conditions of the Creative Commons Attribution (CC BY) license (http://creativecommons.org/licenses/by/4.0/). 